Pacific Journal of Mathematics

CENTRAL MOMENTS FOR ARITHMETIC FUNCTIONS 


\title{
CENTRAL MOMENTS FOR ARITHMETIC FUNCTIONS
}

\author{
Joseph E. ColLison
}

The only central moment considered in probabilistic number theory up until now has been the "variance" of an arithmetic function. This paper considers the case of higher central moments for such functions. It will be shown that if $f$ is an additive complex valued arithmetic function then

$$
\sum_{m \leqq n}|f(m)-A(n)|^{2 K}=O\left(n(\log \log n)^{2 K-2} \sum_{p^{\alpha} \leqq n}\left|f\left(p^{\alpha}\right)\right|^{2 K} p^{-\alpha}\right)
$$

where $K$ is a positive integer and

$$
A(n)=\sum_{p^{\alpha} \leqq n} f\left(p^{\alpha}\right) p^{-\alpha} .
$$

It will also be shown that if $f$ is an additive real valued arithmetic function and $K$ is an odd positive integer, then

$$
\sum_{m \leqq n}(f(m)-A(n))^{K}=O\left(n(\log \log n)^{K-2+1 / K} \sum_{p^{\alpha \leqq n}}\left|f\left(p^{\alpha}\right)\right|^{K} p^{-\alpha}\right) .
$$

1. Preliminaries. Given a fixed positive integer $K$ let $X$ be a $K$-tuple of prime powers $p^{\alpha}$, where the primes need not be distinct. $Y$ is defined similarly. Next we define

$$
\|X\|=\operatorname{Max}\left\{p^{\alpha}: p^{\alpha} \text { is a component of } X\right\}
$$

and $|X|=\Pi p^{\alpha}$ where the product is over those $p^{\alpha}$ which are components of $X$. By $X_{j}$ we shall mean the $j$-tuple consisting of the first $j$ components of $X$, and $\widetilde{X}_{j}$ shall denote the $K-j$-tuple consisting of the last $K-j$ components of $X . X_{j} Y_{k}$ shall denote the first $j$ components of $X$ followed by the first $k$ components of $Y$. By $X_{j} \| m$ we shall mean that $p^{\alpha} \| m$ for all the components of $X_{j}$. If $f$ is an arithmetic function, then we define $F(X)$ to be $\Pi f\left(p^{\alpha}\right)$ where the product is over all the components $p^{\alpha}$ of $X$.

Lemma 1. Given the $M$ distinct prime powers $P_{i}=p_{i}^{\alpha_{i}}, i=1$, $\cdots, M$, and the positive integer $n$,

$$
W(M, n)=n^{-1} \sum_{\substack{k \leqq n \\ P_{i}|| k, i \leqq M}} 1=\prod_{i=1}^{M} P_{i}^{-1}\left(1-p_{i}^{-1}\right)+O\left(n^{-1}\right)
$$

where $\left|O\left(n^{-1}\right)\right| \leqq\left(3 \cdot 2^{M}-1\right) n^{-1}$.

Proof. Let $N=L \prod_{i=1}^{M} P_{i}$ for any positive integer $L$. We will now show by induction on $M$ that for all such $N$

$$
W(M, N)=\prod_{i=1}^{M} P_{i}^{-1}\left(1-p_{i}^{-1}\right)+O\left(N^{-1}\right)
$$


where $\left|O\left(N^{-1}\right)\right| \leqq 3\left(2^{M}-1\right) N^{-1}$. We have

$$
W(1, N)=N^{-1}\left(\left[N / P_{1}\right]-\left[N / P_{1} p_{1}\right]\right)=P_{1}^{-1}-N^{-1}\left[N / P_{1} p_{1}\right]
$$

so that the result holds for $M=1$. Letting

$$
K=\left(\left[L / p_{1}\right]+1\right) \prod_{i=2}^{M} P_{i}
$$

we see that for

$$
W^{\prime}(M, n)=n^{-1} \sum_{P_{i} ! \mid k \leq n \leq 1<i \leqq M} 1
$$

we have

$$
W(M, N)=P_{1}^{-1} W^{\prime}\left(M, N / P_{1}\right)-(K / N) W^{\prime}(M, K)+R
$$

where

$$
R=N_{\substack{-1 \\\left[N \mid P_{1} p_{1}\right]<k \leqq K \\ P_{i} \backslash k, 1<i \leqq M}} 1 \leqq N^{-1}\left(K-\left[N / P_{1} p_{1}\right]\right) \prod_{i=2}^{M} P_{i}^{-1}+N^{-1} \leqq 2 / N .
$$

Using estimates provided by the induction hypothesis we see

$$
P_{1}^{-1} W^{\prime}\left(M, N / P_{1}\right)=P_{1}^{-1} \prod_{i=2}^{M} P_{i}^{-1}\left(1-p_{i}^{-1}\right)+V_{1}(N)
$$

where $\left|V_{1}(N)\right| \leqq 3\left(2^{M-1}-1\right) / N$, and

$$
(K / N) W^{\prime}(M, K)=\left(P_{1}^{-1} p_{1}^{-1}+K N^{-1}-P_{1}^{-1} p_{1}^{-1}\right) \prod_{i=2}^{M} P_{i}^{-1}\left(1-p_{i}^{-1}\right)+V_{2}(N)
$$

where $\left|V_{2}(N)\right| \leqq 3\left(2^{M-1}-1\right) / N$. Since

$$
0 \leqq\left(K N^{-1}-P_{1}^{-1} p_{1}^{-1}\right) \prod_{i=2}^{M} P_{i}^{-1}\left(1-p_{i}^{-1}\right) \leqq L^{-1} P_{1}^{-1} \prod_{i=2}^{M} P_{i}^{-1}=N^{-1}
$$

(1.1) now follows.

Let $N=\left(\left[n \prod_{i=1}^{M} P_{i}^{-1}\right]+1\right) \prod_{i=1}^{M} P_{i}$, so that the first part of the proof applies to $W(M, N)$. Then

$$
\begin{aligned}
\mid W(M, & n)-W(M, N)\left|\leqq \sum_{j=n}^{N-1}\right| W(M, j)-W(M, j+1) \mid \\
& \leqq \sum_{j=n}^{N-1}\left|\frac{1}{j}-\frac{1}{j+1}\right| \sum_{\substack{k \leq j \\
P_{i}|| k, i>0}} 1+\frac{1}{j+1} \sum_{\substack{j<k \leq j+1 \\
P_{i} \| k, i>0}} 1 \\
& \leqq \sum_{j=n}^{N-1}(j+1)^{-1} \prod_{i=1}^{M} P_{i}^{-1}+\sum_{\substack{n<j \leq N \\
P_{i} \| j, i>0}} j^{-1} \\
& \leqq\left(\prod_{i=1}^{M} P_{i}^{-1}\right) \log (N / n)+n^{-1}\left(\left[N \prod_{i=1}^{M} P_{i}^{-1}\right]-\left[n \prod_{i=1}^{M} P_{i}^{-1}\right]\right) \\
& \leqq n^{-1} \log \left(1+n^{-1} \prod_{i=1}^{M} P_{i}\right)^{n \Pi_{i=1}^{M} P_{i}^{-1}}+n^{-1} \leqq 2 n^{-1}
\end{aligned}
$$


which provides the desired result.

LEMMA 2. For $M \geqq 2$ and letting $P=p^{\alpha}$ represent the power of a prime

$$
\sum_{\substack{P_{1} \ldots P_{M}>n \\ P_{i} \leqq n, i \leqq M}} P_{1}^{-1} \cdots P_{M}^{-1} \leqq C_{1} M^{4}\left(\sum_{p \propto \leqq n} p^{-\alpha}\right)^{M-2}
$$

for some absolute constant $C_{1}$.

Proof. Separating the two largest prime powers from the rest we see

$$
\sum_{\substack{P_{1} \\ P_{i} \leqq n}} P_{1}^{-1} \cdots P_{M}^{-1} \leqq M(M-1)\left(\sum_{p^{\alpha} \leqq n} p^{-\alpha}\right)^{M-2}\left(R_{1}+R_{2}\right)
$$

where

$$
R_{1}=\sum_{\substack{p^{\alpha} q^{\beta}>n \\ p^{\alpha} \leqq n, q^{\beta} \leqq n}} p^{-\alpha} q^{-\beta}
$$

is known to be bounded [2; P. 35], and

$$
R_{2}=\sum_{n^{1 / M}<p^{\alpha} \leqq n} p^{-\alpha} \sum_{\left(n / p^{\alpha}\right)^{1,(M-1)}<q^{\beta} \leqq n / p^{\alpha}} q^{-\beta}
$$

With regard to $R_{2}$, we note that for $n p^{-\alpha} \geqq 3^{M}$ the second sum is equal to

$$
\begin{aligned}
& \log \log \left[n / p^{\alpha}\right]-\log \log \left[\left(n / p^{\alpha}\right)^{1 /(M-1)}\right]+O(1) \\
& \quad \leqq \log \log \left(n / p^{\alpha}\right)-\log \log \left(n / p^{\alpha}\right)^{1 / 2 M}+O(1) \\
& \quad=\log 2 M+O(1) .
\end{aligned}
$$

For $n p^{-\alpha}<3^{M}$ we have $q^{\beta}<3^{M}$ and so the second sum in $R_{2}$ is bounded by $\log M+O(1)$ in this case. In a similar manner it can be shown that

$$
\sum_{n^{1 / M<p^{\alpha} \leqq n}} p^{-\alpha} \leqq \log 2 M+O(1) .
$$

Thus there are constants $C_{3}$ and $C_{4}$ for which

$$
\begin{aligned}
R_{1}+R_{2} & \leqq(\log 2 M)^{2}+C_{3} \log 2 M+C_{4} \\
& \leqq M^{2}+C_{3} M+C_{4} .
\end{aligned}
$$

Letting $C_{1}=1+C_{3} / 2+C_{4} / 4$ we obtain the desired result.

2. Even central moments. Now we shall show that 


$$
\sum_{m \leqq n}|f(m)-A(n)|^{2 K}=O\left(n(\log \log n)^{2 K-2} \sum_{p^{\alpha} \leqq n}\left|f\left(p^{\alpha}\right)\right|^{2 K} p^{-\alpha}\right) .
$$

THEOREM 1. Let $f$ be an additive complex valued arithmetic function and let $K$ be a fixed positive integer. Then for $n \geqq 4$

$$
\begin{aligned}
M_{2 K}(n) & =\sum_{m \leqq n}|f(m)-A(n)|^{2 K} \\
& \leqq(2 K) ! 1024^{K} K^{6 K} C_{2} n\left(\sum_{p^{\alpha} \leqq n} p^{-\alpha}\right)^{2 K-2} \sum_{p^{\alpha} \leqq n}\left|f\left(p^{\alpha}\right)\right|^{2 K} p^{-\alpha} .
\end{aligned}
$$

Proof. First we will show that

$$
M_{2 K}(n)=n \sum_{\|X\| ! n, \| Y \mid ! n} F(X) F \overline{(Y) T}(X, Y, n)
$$

where

$$
\begin{aligned}
& T(X, Y, n)=\sum_{j=0}^{K} \sum_{k=0}^{K}(-1)^{j+k}\left(\begin{array}{c}
K \\
j
\end{array}\right)\left(\begin{array}{c}
K \\
k
\end{array}\right)\left|\widetilde{X}_{j} \widetilde{Y}_{k}\right|^{-1} n^{-1} \sum_{\substack{m \leq n \\
x_{j}\left\|\mid m, Y_{k}\right\| m}} 1 . \\
& M_{2 K}(n)=\sum_{j=0}^{K} \sum_{k=0}^{K}(-1)^{j+k}\left(\begin{array}{c}
K \\
j
\end{array}\right)\left(\begin{array}{c}
K \\
k
\end{array}\right) A^{K-j}(n) \overline{A^{K-k}(n)} \\
& \cdot \sum_{m \leqq n}\left(\sum_{\substack{p^{\alpha} \leq n \\
p^{\prime} \prod m}} f\left(p^{\alpha}\right)\right)^{j}\left(\sum_{\substack{q^{\beta} \leq n \\
q^{\beta} ! m}} \overline{f\left(q^{\beta}\right)}\right)^{k} \\
& =\sum_{j=0}^{K} \sum_{k=0}^{K}(-1)^{j+k}\left(\begin{array}{c}
K \\
j
\end{array}\right)\left(\begin{array}{c}
K \\
k
\end{array}\right)\left(\sum_{\left\|\tilde{X}_{j}\right\| \leqq n} F\left(\tilde{X}_{j}\right)\left|\tilde{X}_{j}\right|^{-1}\right) \\
& \cdot\left(\sum_{\left\|\tilde{Y}_{k}\right\| \leqq n} \overline{F\left(\widetilde{Y}_{k}\right)}\left|\widetilde{Y}_{k}\right|^{-1}\right)_{\left\|X_{j}\right\| \leqq n,\left\|Y_{k}\right\| \leqq n} F\left(X_{j}\right) \overline{F\left(Y_{k}\right)} \sum_{\substack{m \leq n \\
X_{j}\left\|m, Y_{k}\right\| m}} 1
\end{aligned}
$$

which equals the right side of (2.2).

Now let $M_{2 K}(n, t)$ denote the restriction of the sum in (2.2) to those $X$ and $Y$ such that exactly $t$ distinct primes occur in the factorization of $|X Y|$. By virtue of the fact that

$$
n^{-1} \sum_{\substack{m \leq n \\ x_{j}\left\|m, Y_{k}\right\| m}} 1 \leqq P^{-1}\left(X_{j}, Y_{k}\right)
$$

where $P\left(X_{j}, Y_{k}\right)$ is a product of the distinct prime powers $p^{\alpha}$ in $X_{j} Y_{k}$ with $\alpha$ being the highest power of $p$ in $X_{j} Y_{k}$, an examination of $T(X, Y, n)$ reveals the fact that in an upper bound of the $(j, k)$ term either $|X Y|$ appears in the denominator or at least one prime is repeated in $X_{j} Y_{k}$. In the latter case, in order for the $(j, k)$ term to be nonzero, a repeated prime must have the same power everywhere it occurs in $X_{j} Y_{k}$. So if $r_{1}, \cdots, r_{t}$, where $r_{1}+\cdots+r_{t}=2 K$, provide the respective number of times the distinct primes $p_{1}, \cdots, p_{t}$ are repeated in $X Y$, and $s(i, 1), \cdots, s(i, u)$, where $s(i, 1)+\cdots+s(i, u)=$ $r_{i}$, provide the respective number of times the distinct powers $\alpha(i, 1)$, 
$\cdots, \alpha(i, u)$ of $p_{\imath}$ occur in $X Y$, then as a result of the above discussion we see that

$$
\begin{aligned}
& |F(X) F(Y) T(X, Y, n)| \\
& \leqq\left(\sum_{j=0}^{K}\left(\begin{array}{c}
K \\
j
\end{array}\right)\right)^{2} \prod_{i=1}^{t} \prod_{k=1}^{u}\left|f\left(p_{i}^{\alpha(i, k)}\right)\right|^{s(i, k)} p_{i}^{-\alpha(i, k)} .
\end{aligned}
$$

Thus we see from (2.2) and the last result that for $t<2 K$

$$
\begin{aligned}
& \left|M_{2 K}(n, t)\right| \leqq n \sum_{\substack{r_{1}+\cdots,+,+r_{t=2 K} \\
r_{i}>0, i=1, \cdots, t}} \frac{(2 K) !}{r_{1} ! \cdots r_{t} !}\left(\sum_{j=0}^{K}\left(\begin{array}{c}
K \\
j
\end{array}\right)\right)^{2} \\
& \cdot \prod_{i=1}^{t} \sum_{p \leqq n} \sum_{u=1}^{r_{i}} \sum_{\substack{s_{1}+\underset{c}{*}+s_{u}=r_{i} \\
s_{k}>0, k=1, \ldots, u}} \frac{r_{i} !}{s_{1} ! \cdots s_{u} !} \prod_{k=1}^{u} \sum_{\alpha \leqq[\log n / \log p]}\left|f\left(p^{\alpha}\right)\right|^{s_{k}} p^{-\alpha} \text {. }
\end{aligned}
$$

Since $\sum p^{-\alpha}$ summed over all positive $\alpha$ is bounded by 1 , it follows by induction on $u$ that

$$
\prod_{k=1}^{u}\left(\sum_{\alpha \leqq[\log n \mid \log p]}\left|f\left(p^{\alpha}\right)\right|^{s_{k}} p^{-\alpha}\right) \leqq 2^{u-1} \sum_{\alpha \leqq[\log n \mid \log p]}\left|f\left(p^{\alpha}\right)\right|^{r_{i}} p^{-\alpha} .
$$

Hence

$$
\begin{aligned}
\left|M_{2 K}(n, t)\right| \leqq & (2 K) ! 4^{K} n \sum_{\substack{r_{1}+\ldots,+r_{i}=2 K \\
r_{i}>0, i=1, \ldots, t}} \prod_{i=1}^{t}\left(\sum_{p}\left|f\left(p^{\alpha}\right)\right|^{r_{i}} p^{-\alpha}\right) \\
& \cdot \sum_{u=1}^{r_{i}} 2^{u-1} \sum_{\substack{s_{1}+\ldots,+s_{1}=r_{i} \\
s_{k}>0, k=1, \ldots, u}} 1 .
\end{aligned}
$$

Using Hölder's inequality and the fact that the last sum is bounded by $r_{i}^{u}$, we see

$$
\begin{aligned}
\left|M_{2 K}(n, t)\right| \leqq & (2 K) ! 4^{K} n \sum_{\substack{r_{1}+\cdots,+r_{t}=2 K \\
r_{i}>0, i=1, \cdots, t}} \prod_{i=1}^{t} 2^{r_{i}} r_{i}^{r_{i}+1}\left(\sum_{p^{\alpha} \leqq n} p^{-\alpha}\right)^{1-r_{i} / 2 K} \\
& \cdot\left(\sum_{p^{\alpha} \leqq n}\left|f\left(p^{\alpha}\right)\right|^{2 K} p^{-\alpha}\right)^{r_{i} / 2 K} \\
\leqq & (2 K) ! 16^{K}(2 K-t+1)^{2 K+2 t} n\left(\sum_{p^{\alpha} \leqq n} p^{-\alpha}\right)^{t-1} \sum_{p^{\alpha} \leqq n}\left|f\left(p^{\alpha}\right)\right|^{2 K} p^{-\alpha} .
\end{aligned}
$$

That is, for $t<2 K$

$$
\begin{array}{r}
\left|M_{2 K}(n, t)\right| \leqq(2 K) ! 64^{K} K^{2 K}\left(4 K^{2}\right)^{t} n \\
\cdot\left(\sum_{p^{\alpha} \leqq n} p^{-\alpha}\right)^{2 K-2} \sum_{p^{\alpha} \leqq n}\left|f\left(p^{\alpha}\right)\right|^{2 K} p^{-\alpha} .
\end{array}
$$

Next we shall consider the case where $t=2 K$. To do this we shall first show that if $p_{X}$ is the smallest prime in $X$ then

$$
|T(X, Y, n)| \leqq K^{2} 4^{K}\left(|X Y| p_{X} q_{Y}\right)^{-1}+3^{2 K+1} n^{-1}
$$


when all the primes in $X Y$ are distinct. By Lemma 1 we see that

$$
T(X, Y, n)=|X Y|^{-1} R(X) R(Y)+O\left(n^{-1}\right)
$$

where

$$
R(X)=\sum_{j=0}^{K}(-1)^{j}\left(\begin{array}{c}
K \\
j
\end{array}\right) \prod_{i=1}^{j}\left(1-p_{i}^{-1}\right)
$$

and $\left|O\left(n^{-1}\right)\right| \leqq 3^{2 K+1} n^{-1}$. Now induction shows

$$
\prod_{i=1}^{j}\left(1-p_{i}^{-1}\right)=1-\sum_{s=1}^{j} p_{s}^{-1} \prod_{i=s+1}^{j}\left(1-p_{i}^{-1}\right)
$$

and hence $|R(X)| \leqq K 2^{K} p_{X}^{-1}$. A similar result holds for $R(Y)$, and hence we have (2.4). Therefore, keeping in mind all primes in $X Y$ are distinct, and using Lemma 2 and Hölder's inequality, we see

$$
\begin{aligned}
& \left|M_{2 K}(n, 2 K)\right| \leqq n \sum_{|X Y| \leqq n}|F(X) F(Y) T(X, Y, n)|
\end{aligned}
$$

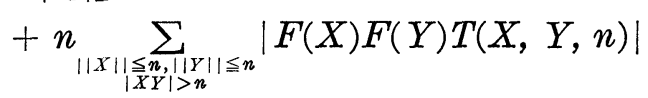

$$
\begin{aligned}
& \leqq n K^{4} 4^{K}\left(\sum_{|| X|| \leqq n}|F(X)| p_{1}^{-1}|X|^{-1}\right)^{2}+3^{2 K+1} \sum_{|X Y| \leqq n} \mid F(X) F(Y)
\end{aligned}
$$

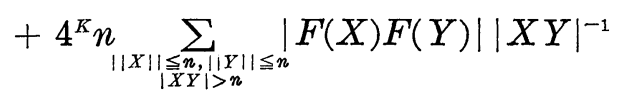

$$
\begin{aligned}
& \leqq n K^{4} 4^{K}\left(\sum_{\|X\| \leqq n}|F(X)|^{2 K}|X|^{-1}\right)^{1 / K}\left(\sum_{\|X\| ! n n} p_{1}^{-2 K /(2 K-1)}|X|^{-1}\right)^{2-1 / K} \\
& +3^{2 K+1}\left(\sum_{|X Y| \leqq n}|F(X) F(Y)|^{2}|X Y|^{-1}\right)^{1 / 2}\left((2 K) ! \sum_{j \leqq n} j\right)^{1 / 2} \\
& +n 4^{K}\left(\sum_{|| X|| \leq n,|| Y|| \leq n}|F(X) F(Y)|^{2}|X Y|^{-1}\right)^{1 / 2}
\end{aligned}
$$

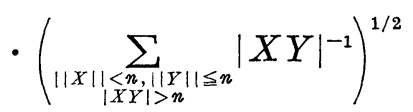

$$
\begin{aligned}
& \leqq n K^{4} 4^{K}\left(\sum_{p^{\alpha} \leqq n} p^{-\alpha-1}\right)^{2}\left(\sum_{p^{\alpha} \leqq n} p^{-\alpha}\right)^{2 K-3+1 / K} \sum_{p^{\alpha} \leqq n}\left|f\left(p^{\alpha}\right)\right|^{2 K} p^{-\alpha} \\
& +\left(3^{2 K+1}(2 K) !+4^{K} C_{1}^{1 / 2}(2 K)^{2}\right) n\left(\sum_{p^{\alpha} \leqq n} p^{-\alpha}\right)^{K-1}
\end{aligned}
$$

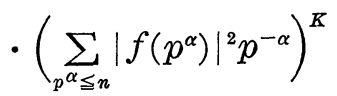

$$
\begin{aligned}
& \leqq\left(K^{4} 4^{K+1}+3^{2 K+1}(2 K) !+4^{K+1} C_{1}^{1 / 2} K^{2}\right) \\
& \cdot n\left(\sum_{p^{\alpha} \leqq n} p^{-\alpha}\right)^{2 K-2} \sum_{p^{\alpha} \leqq n}\left|f\left(p^{\alpha}\right)\right|^{2 K} p^{-\alpha} \\
& \leqq C_{5}(2 K) ! 9^{K} K^{4} n\left(\sum_{p^{\alpha} \leqq n} p^{-\alpha}\right)^{2 K-2} \sum_{p^{\alpha} \leqq n}\left|f\left(p^{\alpha}\right)\right|^{2 K} p^{-\alpha}
\end{aligned}
$$

where $C_{5}=4+C_{1}^{1 / 2}$. 
Combining this last result with (2.3) we now have

$$
\begin{aligned}
\left|M_{2 K}(n)\right| \leqq & (2 K) !\left(C_{5} 9^{K} K^{4}+64^{K} K^{2 K} \sum_{t=1}^{2 K-1}\left(4 K^{2}\right)^{t}\right) \\
& \cdot n\left(\sum_{p^{\alpha} \leqq n} p^{-\alpha}\right)^{2 K-2} \sum_{p^{\alpha} \leqq n}\left|f\left(p^{\alpha}\right)\right|^{2 K} p^{-\alpha}
\end{aligned}
$$

which yields (2.1) for $C_{2}=1 / 3+9 C_{5} / 1024$. This finishes the proof.

3. Odd central moments. If we wish to consider odd central moments, then we must restrict ourselves to additive real valued arithmetic functions. Using the proof of the previous theorem it can be seen that this simplifies matters insofar as double summations become single summations. For example, for odd $K$ and such functions (2.2) becomes

$$
M_{K}(n)=\sum_{m \leqq n}(f(m)-A(n))^{K}=n \sum_{\|X\| \leqq n} F(X) T(X, n)
$$

where

$$
T(X, n)=\sum_{j=0}^{K}(-1)^{j}\left(\begin{array}{c}
K \\
j
\end{array}\right)\left|\widetilde{X}_{j}\right|^{-1} n^{-1} \sum_{\substack{m \leq n \\
X_{j} \| m}} 1 .
$$

If the rest of the proof of the theorem is carried out essentially as it is with minor modifications, it can be seen that for $t<K$

$$
M_{K}(n, t)=O\left(n(\log \log n)^{K-2} \sum_{p^{\alpha} \leqq n}\left|f\left(p^{\alpha}\right)\right|{ }^{K} p^{-\alpha}\right)
$$

as before, and

$$
\begin{aligned}
\left|M_{K}(n, K)\right| \leqq & n K^{2} 2^{K} \sum_{|| X \| \leqq n}|F(X)| p_{1}^{-1}|X|^{-1} \\
& +O\left(n(\log \log n)^{K-2} \sum_{p^{\alpha} \leqq n}\left|f\left(p^{\alpha}\right)\right|^{K} p^{-\alpha}\right) .
\end{aligned}
$$

Now Hölder's inequality shows that

$$
\begin{aligned}
\sum_{\|X\| \leqq n}|F(X)| p_{1}^{-1}|X|^{-1} \leqq & \left(\sum_{\|X\| \leqq n}|F(X)|^{K}|X|^{-1}\right)^{1 / K} \\
& \cdot\left(\sum_{\|X\| \leqq n} p_{1}^{-K /(K-1)}|X|^{-1}\right)^{1-1 / K} \\
\leqq & 1.3\left(\sum_{p^{\alpha} \leqq n} p^{-\alpha}\right)^{K-2+1 / K} \sum_{p^{\alpha} \leqq n}\left|f\left(p^{\alpha}\right)\right|^{K} p^{-\alpha}
\end{aligned}
$$

since $\sum p^{-\alpha-1} \leqq 1.3$. Hence we have:

THEOREM 2. If $f$ is an additive real valued function and $K$ $i s$ an odd integer, then 


$$
\sum_{m \leqq n}(f(m)-A(n))^{K}=B_{K}(n) n\left(\sum_{p^{\alpha} \leqq n} p^{-\alpha}\right)^{K-2+1 / K} \sum_{p^{\alpha} \leqq n}\left|f\left(p^{\alpha}\right)\right|^{K} p^{-\alpha}
$$

where $\overline{\lim } B_{K}(n) \leqq 1.3 K^{2} 2^{K}$.

This increases the exponent of $\sum p^{-\alpha}$ by $1 / K$ relative to Theorem 1 , but in general it cannot be avoided as the following argument shows. It is known [3; p. 201] that

$$
\sum_{p \leqq n} g(p) \sim \int_{9}^{n} g(x)(\log x)^{-1} d x
$$

provided $g(x) / \log x$ for $x \geqq 9$ is positive, nonincreasing, and has the limit 0 as $x \rightarrow \infty$,

$$
\int_{9}^{\infty} g(x)(\log x)^{-1} d x \quad \text { diverges }
$$

and

$$
\int_{9}^{\infty} g(x)(\log x)^{-1} e^{-(\log x)^{1 / 14}} \quad \text { converges . }
$$

These conditions are satisfied by $g_{1}(p)=p^{-1}|\log \log p|^{-1 / K}$ and $g_{2}(p)=$ $p^{-1}|\log \log p|^{-1}$. Hence, for $f(p)=(\log \log p)^{-1 / K}$ and $f\left(p^{\alpha}\right)=0$ for $\alpha>1$, we see that

$$
\sum_{\|X\| \leq n}|F(X)| p_{1}^{-1}|X|^{-1} \geqq C_{6}\left(\sum_{p \leqq n} g_{1}(p)\right)^{K-1} \sim C_{6}\left(\frac{K}{K-1}\right)^{K-1}(\log \log n)^{K-2+1 / K}
$$

and

$$
\sum_{p^{\alpha} \leqq n}\left|f\left(p^{\alpha}\right)\right|^{K} p^{-\alpha}=\sum_{p \leqq n} g_{2}(p) \sim \log \log \log n .
$$

In the light of (3.1) this shows the desired result.

\section{REFERENCES}

1. J. Collison, A variance property for arithmetic functions, Pacific J. Math., 63 (1976), 347-355.

2. J. Kubilius, Probabilistic Methods in the Theory of Numbers, Translations of Mathematical Monographs, Amer. Math. Soc. Vol. 11, Providence, R. I., 1964.

3. E. Landau, Handbuch der Lehre von der Verteilung der Primzahlen, Vol. 1, Leipzig: Teubner Verlagsgesellschaft, 1909. Reprinted, Chelsea Publishing Company, New York, 1974.

Received May 19, 1977.

Baruch College, City University of New York

NEW YoRK, NY 10010 


\title{
PACIFIC JOURNAL OF MATHEMATICS
}

\section{EDITORS}

RICHARD ARENS (Managing Editor)

University of California

Los Angeles, CA 90024

Charles W. Curtis

University of Oregon

Eugene, OR 97403

C. C. MOORE

University of California

Berkeley, CA 94720
J. DUGUNDJI

Department of Mathematics

University of Southern California

Los Angeles, CA 90007

R. Finn and J. Milgram

Stanford University

Stanford, CA 94305

\section{ASSOCIATE EDITORS}
E. F. BECKENBACH
B. H. Neumann
F. WOLF
K. YosHidA

\section{SUPPORTING INSTITUTIONS}

\author{
UNIVERSITY OF BRITISH COLUMBIA \\ CALIFORNIA INSTITUTE OF TECHNOLOGY \\ UNIVERSITY OF CALIFORNIA \\ MONTANA STATE UNIVERSITY \\ UNIVERSITY OF NEVADA, RENO \\ NEW MEXICO STATE UNIVERSITY \\ OREGON STATE UNIVERSITY \\ UNIVERSITY OF OREGON
}

\author{
UNIVERSITY OF SOUTHERN CALIFORNIA \\ STANFORD UNIVERSITY \\ UNIVERSITY OF HAWAII \\ UNIVERSITY OF TOKYO \\ UNIVERSITY OF UTAH \\ WASHINGTON STATE UNIVERSITY \\ UNIVERSITY OF WASHINGTON
}

The Supporting Institutions listed above contribute to the cost of publication of this Journal, but they are not owners or publishers and have no responsibility for its content or policies.

Mathematical papers intended for publication in the Pacific Journal of Mathematics should be in typed form or offset-reproduced, (not dittoed), double spaced with large margins. Please do not use built up fractions in the text of the manuscript. However, you may use them in the displayed equations. Underline Greek letters in red, German in green, and script in blue. The first paragraph or two must be capable of being used separately as a synopsis of the entire paper. Items of the bibliography should not be cited there unless absolutely necessary, in which case they must be identified by author and journal, rather than by item number. Manuscripts, in triplicate, may be sent to any one of the editors. Please classify according to the scheme of Math. Reviews, Index to Vol. 39. All other communications should be addressed to the managing editor, or Elaine Barth, University of California, Los Angeles, California, 90024.

50 reprints to each author are provided free for each article, only if page charges have been substantially paid. Additional copies may be obtained at cost in multiples of 50 .

The Pacific Journal of Mathematics is issued monthly as of January 1966. Regular subscription rate: $\$ 72.00$ a year (6 Vols., 12 issues). Special rate: $\$ 36.00$ a year to individual members of supporting institutions.

Subscriptions, orders for numbers issued in the last three calendar years, and changes of address should be sent to Pacific Journal of Mathematics, P.O. Box 969, Carmel Valley, CA 93924, U.S.A. Older back numbers obtainable from Kraus Periodicals Co., Route 100, Millwood, NY 10546.

PUBLISHED BY PACIFIC JOURNAL OF MATHEMATICS, A NON-PROFIT CORPORATION

Printed at Kokusai Bunken Insatsusha (International Academic Printing Co., Ltd.). 8-8, 3-chome, Takadanobaba, Shinjuku-ku, Tokyo 160, Japan.

Copyright (C) 1978 by Pacific Journal of Mathematics Manufactured and first issued in Japan 


\section{Pacific Journal of Mathematics}

Vol. 77, No. $2 \quad$ February, 1978

Graham Donald Allen, Duals of Lorentz spaces ................... 287

Gert Einar Torsten Almkvist, The number of nonfree components in the decomposition of symmetric powers in characteristic p .......... 293

John J. Buoni and Bhushan L. Wadhwa, On joint numerical ranges ...... 303

Joseph Eugene Collison, Central moments for arithmetic functions . . . . . . 307

Michael Walter Davis, Smooth G-manifolds as collections of fiber

bundles ........................................ 315

Michael E. Detlefsen, Symmetric sublattices of a Noether lattice......... 365

David Downing, Surjectivity results for $\phi$-accretive set-valued

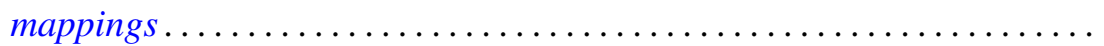

David Allyn Drake and Dieter Jungnickel, Klingenberg structures and partial designs. II. Regularity and uniformity ................. 389

Edward George Effros and Jonathan Rosenberg, $C^{*}$-algebras with approximately inner flip .......................... 417

Burton I. Fein, Minimal splitting fields for group representations. II. . . . . 445

Benjamin Rigler Halpern, A general coincidence theory ............. 451

Masamitsu Mori, A vanishing theorem for the mod $p$ Massey-Peterson spectral sequence ................................ 473

John C. Oxtoby and Vidhu S. Prasad, Homeomorphic measures in the

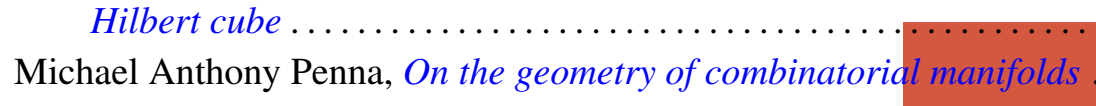

Robert Ralph Phelps, Gaussian null sets and differentiability of Lipschitz map on Banach spaces........................

Herbert Silverman, Evelyn Marie Silvia and D. N. Telage, Locally univalent functions and coefficient distortions...

Donald Curtis Taylor, The strong bidual of $\Gamma(K)$

Willie Taylor, On the oscillatory and asymptotic behavior of solutions of fifth order selfadjoint differential equations ...........

Fu-Chien Tzung, Sufficient conditions for the set of Hausdorff compactifications to be a lattice. 